\title{
Ultra High Performance Liquid Chromatography Method for the Determination of Two Recently FDA Approved TKIs in Human Plasma Using Diode Array Detection
}

\author{
Marwa Fouad, ${ }^{1}$ Maxime Helvenstein, ${ }^{2}$ and Bertrand Blankert ${ }^{2}$ \\ ${ }^{1}$ Pharmaceutical Chemistry Department, Faculty of Pharmacy, Cairo University, Kasr El-Aini Street, Cairo 11562, Egypt \\ ${ }^{2}$ Laboratory of Pharmaceutical Analysis, Faculty of Medicine and Pharmacy, Research Institute for Health Sciences and Technology, \\ University of Mons (UMONS), Place du Parc 20, 7000 Mons, Belgium
}

Correspondence should be addressed to Bertrand Blankert; bertrand.blankert@umons.ac.be

Received 1 March 2015; Accepted 20 April 2015

Academic Editor: Mohamed Abdel-Rehim

Copyright (c) 2015 Marwa Fouad et al. This is an open access article distributed under the Creative Commons Attribution License, which permits unrestricted use, distribution, and reproduction in any medium, provided the original work is properly cited.

\begin{abstract}
Generally, tyrosine kinase inhibitors have narrow therapeutic window and large interpatient variability compared to intrapatient variability. In order to support its therapeutic drug monitoring, two fast and accurate methods were developed for the determination of recently FDA approved anticancer tyrosine kinase inhibitors, afatinib and ibrutinib, in human plasma using ultra high performance liquid chromatography coupled to PDA detection. Diclofenac sodium was used as internal standard. The chromatographic separation was achieved on an Acquity UPLC BEH C18 analytical column using a mobile phase combining ammonium formate buffer and acetonitrile at a constant flow rate of $0.4 \mathrm{~mL} / \mathrm{min}$ using gradient elution mode. A $\mu$ SPE (solid phase extraction) procedure, using Oasis MCX $\mu$ Elution plates, was processed and it gave satisfying and reproducible results in terms of extraction yields. Additionally, the methods were successfully validated using the accuracy profiles approach $(\beta=95 \%$ and acceptance limits $= \pm 15 \%$ ) over the ranges $5-250 \mathrm{ng} / \mathrm{mL}$ for afatinib and from 5 to $400 \mathrm{ng} / \mathrm{mL}$ for ibrutinib in human plasma.
\end{abstract}

\section{Introduction}

In recent years, multiple tyrosine kinase inhibitors (TKIs) have been approved as monotherapy for cancer treatment. These targeted anticancer compounds are directed against tyrosine kinases, which play an essential role in the transduction of growth signals in cells [1]. Since they specifically inhibit cellular processes that are deregulated in various types of tumor cells, they were initially considered to be less toxic than conventional chemotherapy. However, it appears that, similar to conventional chemotherapy, dose interruptions or reductions due to adverse effects are necessary in a large number of patients which indicates that TKIs have a narrow therapeutic window [2-5]. Additionally, high pharmacokinetic variability (both interpatient and intrapatient) in plasma levels was found, which results in highly variable plasma concentrations and consequently drug-exposure. This suggests that plasma levels may be more predictive than absolute dose in predicting treatment response and adverse effects [6-11]. TKIs have most of the characteristics that are required for therapeutic drug monitoring (TDM), such as a narrow therapeutic window, large interpatient variability compared to intrapatient variability, and the chronic use until disease progression [12]. Therefore, TDM might be a very promising tool for this new class of drugs in order to improve treatment benefit by reducing drug toxicity, reducing drug resistance, and increasing efficacy. Moreover, rational quantification of TKI plasma levels can provide a better understanding of treatment failure or suboptimal response in patients receiving TKIs [13]. Thus, to support clinical pharmacological studies and to address observations in daily clinical practice, it was essential to develop and validate a quantitative bioanalytical assay to quantify TKIs in plasma.

Afatinib (AFA) is an orally administered, irreversible tyrosine kinase inhibitor of the ErbB family of receptors and it is reported to be a potential treatment for a variety of solid tumors. It is potent and highly selective as it irreversibly inhibits signaling from all ErbB family dimers: ErbB1, 


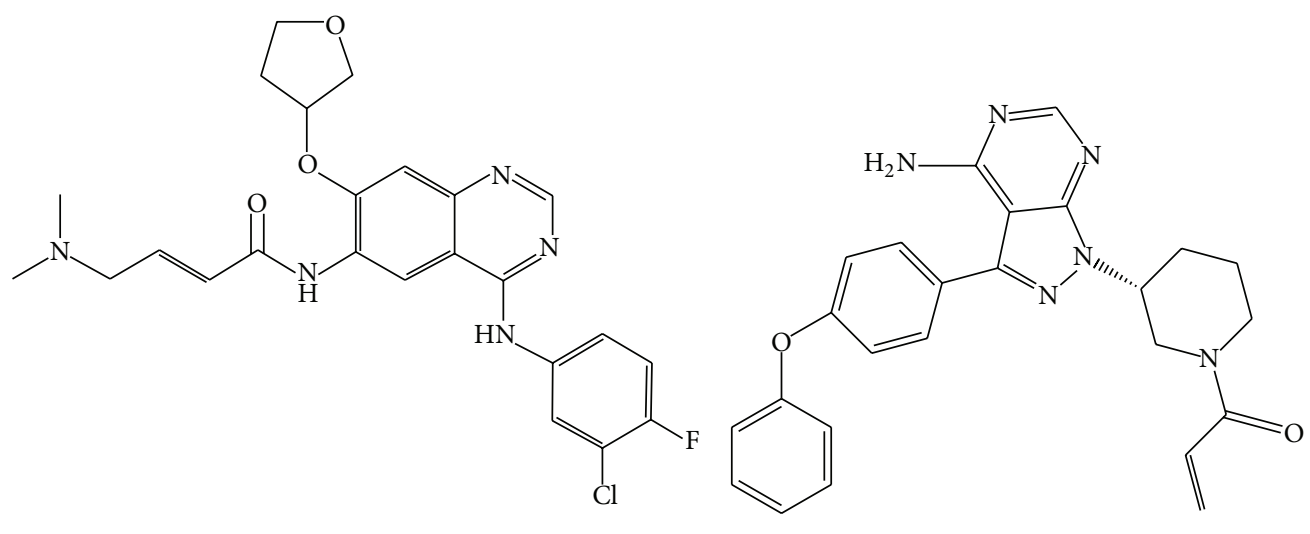

(a)

(b)<smiles>O=C(O)Cc1ccccc1Nc1c(Cl)cccc1Cl</smiles>

(c)

FIgURE 1: Chemical structures of (a) afatinib, (b) ibrutinib, and (c) diclofenac.

ErbB2, ErbB3, and ErbB4 [14-16]. As these receptors are involved in cell proliferation, differentiation, and apoptosis, their inhibition may play a critical role in the prevention of tumor growth and spread, including epidermal growth factor receptor- (EGFR-) mutation-positive non-small cell lung cancer (NSCLC) and metastatic head and neck cancer [17-21].

Ibrutinib (IBR) irreversibly inhibits Bruton's tyrosine kinase (BTK), an enzyme responsible for proliferation, differentiation, apoptosis, and cell migration of B-cells, by binding to a cysteine residue (Cys-481) in the BTK active site [22, 23]. Because constitutive activation of $\mathrm{B}$-cell receptor signaling is important for survival of malignant B-cells, BTK inhibition results in decreased malignant B-cell proliferation and survival. Nonclinical studies show that IBR also inhibits B-cell migration and substrate adhesion in vitro. It is proposed for the treatment of patients with relapsed or refractory mantle cell lymphoma (MCL) and chronic lymphocytic leukemia (CLL). It is only approved for use in patients who have received at least one prior therapy, limiting its use as a potential frontline therapy $[24,25]$.

A publication from Stopfer et al. in 2012 describes a HPLC-MS/MS method for AFA pharmacokinetics assessment, but without considering a real validation procedure from the analytical point of view [26]. It is why the present work, to the best of our knowledge, proposes the first fully validated methods for the quantification of two recently FDA approved TKIs [27-30], AFA and IBR, in biological matrix. Thus, the aim of our study was the development and validation of simple, sensitive, rapid, and reliable UPLC-DAD methods, suitable for the quantification of AFA and IBR in human plasma. The validation results herein of the suggested inexpensive method for the assay of these drugs can be broadly applicable to clinical routine and efficient for a wider panel of bioclinical laboratories. The described validations were performed according to accuracy profile strategy $(\beta$ expectation tolerance interval).

\section{Materials and Methods}

2.1. Reagents. Afatinib, [N-[4-[(3-chloro-4-fluorophenyl)amino]7-[[(3S)-tetrahydro-3-furanyl] oxy]-6-quinazolinyl]-4(dimethylamino)-2-butenamide] (Figure 1(a)), and Ibrutinib, [1[(3R)-3-[4-Amino-3-(4-phenoxyphenyl)-1H-pyrazolo[3,4d]pyrimidin-1-yl]piperidin-1-yl]prop-2-en-1-one] (Figure 1(b)), were purchased from Selleck Chemicals (Houston, TX, USA). Diclofenac sodium [2-(2-(2,6-dichlorophenylamino)phenyl)acetic acid sodium salt] (Figure 1(c)) came from ABC Chemicals (Wauthier-Braine, Belgium).

Phosphoric acid and methanol (HPLC grade) came from ChemLab (Zedelgem, Belgium). Ammonium hydroxide came from VWR (Fontenay-sous-Bois, France). Ammonium formate was purchased from Sigma-Aldrich (St. Louis, MO, USA). Formic acid and acetonitrile (UPLC grade) came from Biosolve (Valkenswaard, Netherlands). Ultrapure water $(18.2 \mathrm{M} \Omega \mathrm{cm})$ was obtained with a Reference A+ Milli Q water purification system (Millipore, Brussels, Belgium).

2.2. Instrumental Conditions. Chromatographic analyses were performed on a Waters Acquity H-Class UPLC System (MA, USA) equipped with an Acquity UPLC BEH C18 $(1.7 \mu \mathrm{m} ; 2.1 \mathrm{~mm} \times 50 \mathrm{~mm})$ as analytical column, maintained at $40^{\circ} \mathrm{C}$. Sample temperature was kept at $4^{\circ} \mathrm{C}$. An optimized gradient elution was carried out at a constant flow rate 
of $0.4 \mathrm{~mL} / \mathrm{min}$. The mobile phase combines ammonium formate buffer ( $4 \mathrm{mM}$, pH 3.2 adjusted with formic acid) and acetonitrile $(\mathrm{ACN})$. For AFA, the percentage of ACN was initially set at $5 \%$ and regularly increased up to $22 \%$ within $1 \mathrm{~min}$. Thereafter, it was gradually increased to $80 \%$ until $2.7 \mathrm{~min}$, kept constant until $2.9 \mathrm{~min}$, and quickly decreased to $5 \%$ at $3.0 \mathrm{~min}$. For IBR, the percentage of ACN was initially set at $5 \%$ and regularly increased up to $37 \%$ within $1 \mathrm{~min}$. Thereafter, it was gradually increased to $90 \%$ until $2.7 \mathrm{~min}$, kept constant until $2.9 \mathrm{~min}$, and quickly decreased to $5 \%$ at $3.0 \mathrm{~min}$. The total run time was $4.0 \mathrm{~min}$ and the injection volume was fixed at $10 \mu \mathrm{L}$. The DAD detector was set at $268 \mathrm{~nm}$. All data acquisition and chromatograms analyses were performed using Empower Software 3.0 (Waters).

2.3. Stock and Standard Solutions. Stock solutions of AFA $(0.5 \mathrm{mg} / \mathrm{mL})$, IBR $(0.5 \mathrm{mg} / \mathrm{mL})$, and diclofenac sodium internal standard (IS) $(0.1 \mathrm{mg} / \mathrm{mL})$ were made in methanol. Working solutions $(40 \mu \mathrm{g} / \mathrm{mL}$ for AFA and IBR, $10 \mu \mathrm{g} / \mathrm{mL}$ for IS) were prepared by diluting the adequate volume in methanol. To prepare the standard solutions, working solutions of AFA and IBR were serially diluted with methanol to obtain the desired concentrations: $0.2-10 \mu \mathrm{g} / \mathrm{mL}$ for AFA and $0.2-$ $16 \mu \mathrm{g} / \mathrm{mL}$ for IBR. Then, equal volumes of IS working solution and each of AFA and IBR standard solutions were mixed.

2.4. Sample Preparation. For the development and validation steps, plasma was thawed at room temperature and centrifuged at about $1920 \mathrm{RCF}$ at $4^{\circ} \mathrm{C}$ for $10 \mathrm{~min}$. Samples were prepared by spiking $100 \mu \mathrm{L}$ of plasma with $5 \mu \mathrm{L}$ prepared solution mixture of the target analyte and internal standard and diluted with $900 \mu \mathrm{L}$ or $100 \mu \mathrm{L}$ purified water for SPE or $\mu \mathrm{SPE}$, respectively. Finally, $20 \mu \mathrm{L}$ phosphoric acid was added and samples were vortex mixed for 15 seconds.

2.5. Solid Phase Extraction (SPE). Sample solutions were applied to OASIS MCX cartridges which had previously been conditioned twice with $1 \mathrm{~mL}$ methanol and equilibrated with $1 \mathrm{~mL}$ purified water, successively. The cartridge was washed with $1 \mathrm{~mL} 2 \%$ formic acid in water $(\mathrm{v} / \mathrm{v})$. Elution was carried out by $1 \mathrm{~mL}$ elution mixture: acetonitrile/methanol/ammonium hydroxide $(57: 38: 5)$, and the eluate was collected and evaporated to dryness using gentle stream of nitrogen. The residue was reconstituted with $100 \mu \mathrm{L}$ methanol.

For the validation procedure, Oasis MCX $\mu$ Elution Plates (30 $\mu \mathrm{M}$, Waters) were used with an extraction plate manifold (Waters, Milford, MA, USA). Each well of the plate was conditioned two times with $200 \mu \mathrm{L}$ of methanol and equilibrated with $100 \mu \mathrm{L}$ of ultrapure water. The samples (prepared as explained in Section 2.4) were loaded in each well. Formic acid (2\%, v/v in water) washes were then performed. Elution was done in collection plates with $50 \mu \mathrm{L}$ of elution mixture, acetonitrile/methanol/ammonium hydroxide (57:38:5), and quickly diluted with $50 \mu \mathrm{L}$ of formic acid $4 \%(\mathrm{v} / \mathrm{v})$ in water. During the validation step, recoveries at all the levels of concentration were calculated on three consecutive days. Areas of the peaks after MCX extraction were compared to those of standard solutions.
2.6. Validation Methodology. The developed UPLC method was validated using accuracy profiles concept. The Société Française des Sciences et Techniques Pharmaceutiques (SFSTP) commissions elaborated validation guidelines to help scientists to apply harmonized regulatory recommendations and to validate their analytical and biopharmaceutical procedures [31-33]. Their novel validation strategy was based on the total error (bias + standard deviation) and the accuracy profiles decision tool. Currently, this new protocol of validation becomes more attractive and knows a wider spreading among the scientific community [34-40].

Briefly, a procedure can be qualified as acceptable if the difference between every measurement $(x)$ of a sample and its "true value" $(\mu T)$ is inside the acceptance limits $\lambda$ (predefined by the analyst depending to the objective of the method). The probability that the results will be in these acceptance limits should be superior or equal to a probability $\beta$. It can be translated into the following [31-33]:

$$
P(|x-\mu T|<\lambda) \geq \beta .
$$

For each analyte, 6 calibration standards (CS) and 6 validation standards (VS) are realized in human plasma. The concentration range for CS and VS for AFA and IBR in plasma ranged from 5 to $250 \mathrm{ng} / \mathrm{mL}$ and from 5 to $400 \mathrm{ng} / \mathrm{mL}$, respectively. The concentration of IS was $250 \mathrm{ng} / \mathrm{mL}$. Each CS and VS was prepared on three consecutive days and analyzed each day in triplicate for CS and four times for VS. $\beta$-expectation tolerance intervals were computed for each analyte using $\beta$ set at $95 \%$. All data were computed with Excel software (Microsoft, USA). Accuracy profiles were drawn using acceptance limits at $\pm 15 \%$ for the concentration range.

\section{Results and Discussion}

3.1. Developing the $\mu S P E$ and UPLC Method. During the optimization cycle, several chromatographic conditions were attempted using Acquity UPLC BEH C18 $(1.7 \mu \mathrm{m} ; 2.1 \mathrm{~mm}$ $\times 50 \mathrm{~mm}$ ). Various mobile phase compositions like ACN with $0.1 \%$ formic acid and ACN with ammonium formate buffer ( $4 \mathrm{mM}, \mathrm{pH} 3.2$ ) in different proportions were tried in an isocratic and gradient mode (data not shown). The final composition chosen is a mixture of ACN and ammonium formate buffer ( $4 \mathrm{mM}, \mathrm{pH}$ 3.2) for both compounds using a gradient elution mode. The chromatographic separation performed under these conditions is efficient and gives rise to well-shaped peaks with a rapid time analysis shorter than 4 min.

Selecting a proper detection wavelength is of great importance to ensure precise detection of the analytes and to achieve the goal of maximizing absorption and minimizing interference. The UV-Vis spectra acquired with the DAD detector exhibited a major absorption band at 258 for AFA and IBR but $268 \mathrm{~nm}$ was chosen as the wavelength of detection because it was found that minimum interferences have arisen from plasma components at this wavelength while keeping reasonable peak areas.

The chromatograms registered for AFA and IBR, in human plasma, show sharp and symmetrical peaks; the 
TABLE 1: Validation data of linear regression of AFA and IBR in human plasma.

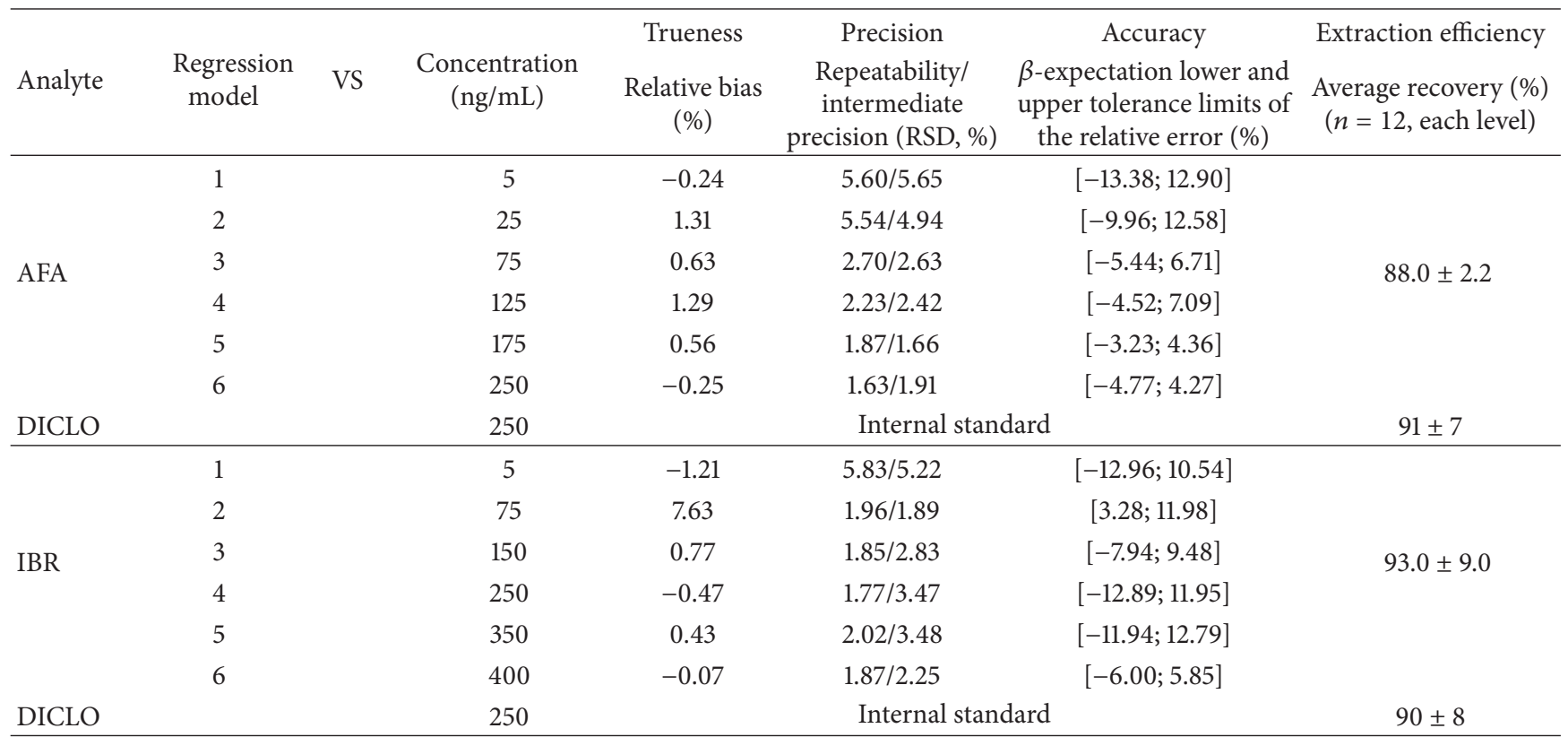

$n$ : number of repetitions.

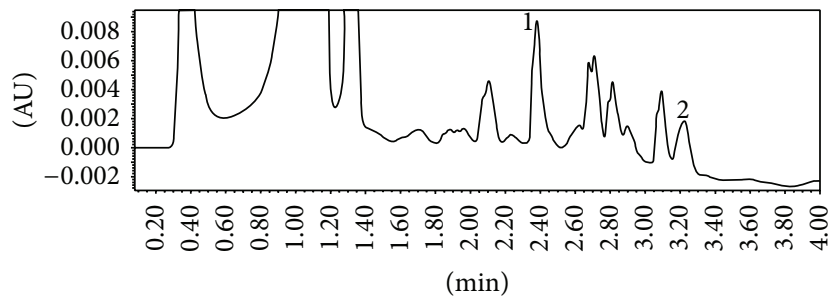

FIGURE 2: Typical chromatogram of human plasma sample spiked with (1) afatinib at $250 \mathrm{ng} / \mathrm{mL}$ (RT: $2.38 \mathrm{~min}$ ) and (2) diclofenac at $250 \mathrm{ng} / \mathrm{mL}$ (RT: $3.22 \mathrm{~min}$ ).

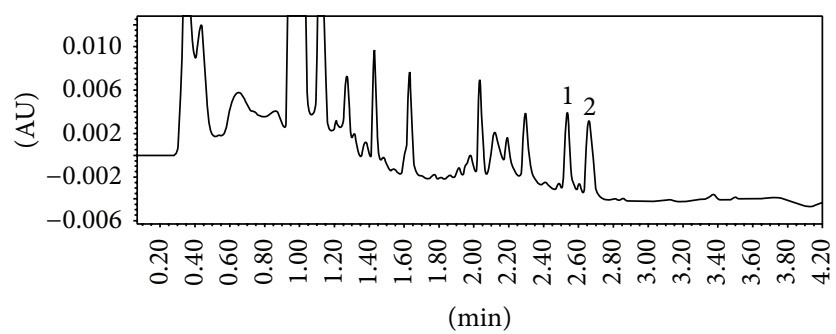

FIGURE 3: Typical chromatogram of human plasma sample spiked with (1) ibrutinib at $200 \mathrm{ng} / \mathrm{mL}$ (RT: $2.54 \mathrm{~min}$ ) and (2) diclofenac at $250 \mathrm{ng} / \mathrm{mL}$ (RT: $2.66 \mathrm{~min}$ ).

targeted compounds are separated with high resolution and selectivity, free from any interference (Figures 2 and 3 ).

The selected SPE stationary phase (MCX) is an ion exchange mode, specially designed for weakly basic compounds. Classical SPE MCX cartridges were only used in the preliminary phase to check if the MCX sorbent is the appropriate stationary phase for the extraction of target analytes and IS from human plasma. The selectivity of MCX stationary phase allowed a good resolution of the analyte from plasma matrix peaks. Consequently, Oasis MCX $\mu$ Elution plates were used for the validation procedure and it gave good chromatograms with well resolved peaks. $\mu$ Elution SPE presents the advantages to avoid any studied compounds degradation and no evaporation step is required which limits sample losses and saves time. Mean recoveries, with $\mu \mathrm{SPE}$ MCX extraction, provided satisfying yields at $88.0 \pm 2.2$ and $93.0 \pm 9.0$ for AFA and IBR, respectively (see Table 1).

3.2. Validation. Using the experimental data results from the validation procedure, we computed trueness (expressed in terms of relative bias (\%)), precision (intermediate precision and repeatability), and accuracy. For each analyte, tolerance intervals limits were calculated $(\beta=95 \%)$ and accuracy profiles were drawn. The linear regression model allowed the validation of each analytical quantification method on the whole range of concentration (data of interest are summarized in Table 1). Figures 4 and 5 show accuracy profiles for each compound considered with linear regression model. As all tolerance intervals are comprised within the acceptance limits, this graphical tool permits to conclude to the validation of the developed quantification methods on the whole tested concentration ranges: from 5 to $250 \mathrm{ng} / \mathrm{mL}$ for AFA and from 5 to $400 \mathrm{ng} / \mathrm{mL}$ for IBR. The LLOQ on plasma assays for AFA and IBR are presented both to be of $5 \mathrm{ng} / \mathrm{mL}$.

\section{Conclusion}

We have developed and validated two fast UPLC methods coupled to $\mathrm{DAD}$ for the quantitative analysis of two tyrosine kinase inhibitors (afatinib and ibrutinib) in human plasma. Human plasma spiked with these TKIs was successfully 


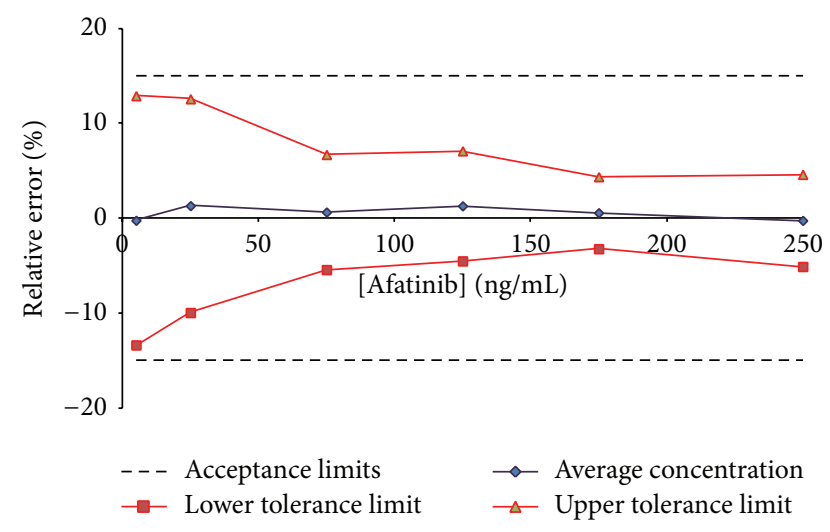

FIgURE 4: Accuracy profile for afatinib in human plasma; $\beta$ expectation tolerance interval set at $95 \%$ and $\lambda$ acceptance limits set at $\pm 15 \%$. All tested concentrations were validated (from 5 to $250 \mathrm{ng} / \mathrm{mL}$ ).

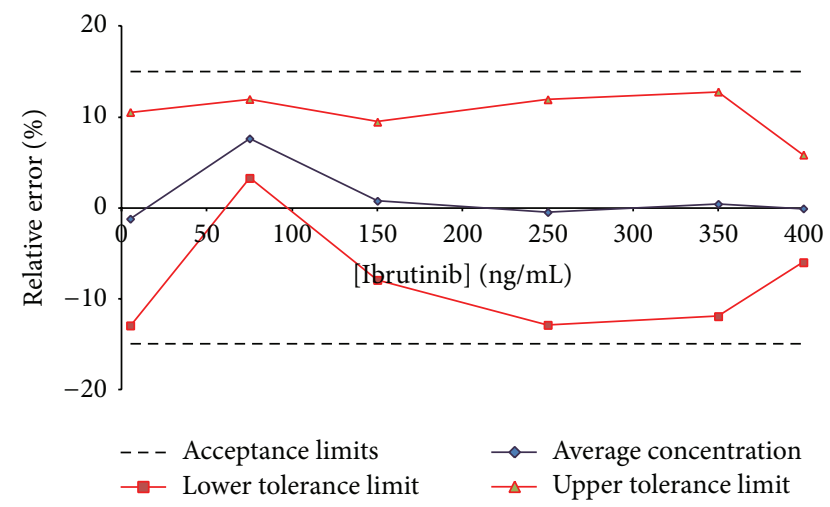

Figure 5: Accuracy profile for ibrutinib in human plasma; $\beta$ expectation tolerance interval set at $95 \%$ and $\lambda$ acceptance limits set at $\pm 15 \%$. All tested concentrations were validated (from 5 to $400 \mathrm{ng} / \mathrm{mL}$ ).

extracted using Oasis MCX 96-well $\mu$ Elution Plates. A linear range from 5 to $250 \mathrm{ng} / \mathrm{mL}$ and from 5 to $400 \mathrm{ng} / \mathrm{mL}$ has been successfully validated for afatinib and ibrutinib with high accuracy and precision using accuracy profile strategy. The method is sensitive with low LLOQ. To the best of our knowledge, it is the first time that such analytical protocol (including $\mu \mathrm{SPE}$, UPLC and a fully validation) is described for these two TKis and seems to be the first description of this approach for these drugs. It represents perhaps a valuable and cheaper methodology that can be implemented in routine therapeutic drug monitoring across more laboratories.

\section{Conflict of Interests}

The authors declare that there is no conflict of interests regarding the publication of this paper.

\section{Acknowledgment}

This work was supported by grant from Erasmus Mundus, Fatima Al Fihri Project.

\section{References}

[1] D. S. Krause and R. A. van Etten, "Tyrosine kinases as targets for cancer therapy," The New England Journal of Medicine, vol. 353, pp. 172-187, 2005.

[2] T. E. Hutson, I. D. Davis, J.-P. H. Machiels et al., "Efficacy and safety of pazopanib in patients with metastatic renal cell carcinoma," Journal of Clinical Oncology, vol. 28, no. 3, pp. 475480, 2010.

[3] G. D. Demetri, A. T. van Oosterom, C. R. Garrett et al., "Efficacy and safety of sunitinib in patients with advanced gastrointestinal stromal tumour after failure of imatinib: a randomised controlled trial," The Lancet, vol. 368, no. 9544, pp. 1329-1338, 2006.

[4] B. J. Druker, M. Talpaz, D. J. Resta et al., "Efficacy and safety of a specific inhibitor of the BCR-ABL tyrosine kinase in chronic myeloid leukemia," The New England Journal of Medicine, vol. 344, no. 14, pp. 1031-1037, 2001.

[5] T. E. Hutson, J. Bellmunt, C. Porta et al., "Long-term safety of sorafenib in advanced renal cell carcinoma: follow-up of patients from phase III TARGET,' European Journal of Cancer, vol. 46, no. 13, pp. 2432-2440, 2010.

[6] N. P. van Erp, S. D. Baker, A. S. Zandvliet et al., "Marginal increase of sunitinib exposure by grapefruit juice," Cancer Chemotherapy and Pharmacology, vol. 67, no. 3, pp. 695-703, 2011.

[7] A. Broniscer, S. J. Baker, C. F. Stewart et al., "Phase Ii and Pharmacokinetic studies of erlotinib administered concurrently with radiotherapy for children, adolescents, and young adults with high-grade glioma," Clinical Cancer Research, vol. 15, no. 2, pp. 701-707, 2009.

[8] S. Bouchet, E. Chauzit, D. Ducint et al., "Simultaneous determination of nine tyrosine kinase inhibitors by 96 -well solid-phase extraction and ultra performance LC/MS-MS," Clinica Chimica Acta, vol. 412, no. 11-12, pp. 1060-1067, 2011.

[9] G. D. Demetri, P. G. Casali, J.-Y. Blay et al., "A phase I study of single-agent nilotinib or in combination with imatinib in patients with imatinib-resistant gastrointestinal stromal tumors," Clinical Cancer Research, vol. 15, no. 18, pp. 5910-5916, 2009.

[10] H. I. Hurwitz, A. Dowlati, S. Saini et al., "Phase I trial of pazopanib in patients with advanced cancer," Clinical Cancer Research, vol. 15, no. 12, pp. 4220-4227, 2009.

[11] J. F. T. Teng, V. H. Mabasa, and M. H. H. Ensom, "The role of therapeutic drug monitoring of imatinib in patients with chronic myeloid leukemia and metastatic or unresectable gastrointestinal stromal tumors," Therapeutic Drug Monitoring, vol. 34, no. 1, pp. 85-97, 2012.

[12] M. E. De Jonge, A. D. R. Huitema, J. H. M. Schellens, S. Rodenhuis, and J. H. Beijnen, "Individualised cancer chemotherapy: strategies and performance of prospective studies on therapeutic drug monitoring with dose adaptation: a review," Clinical Pharmacokinetics, vol. 44, no. 2, pp. 147-173, 2005.

[13] S. Picard, K. Titier, G. Etienne et al., "Trough imatinib plasma levels are associated with both cytogenetic and molecular responses to standard-dose imatinib in chronic myeloid leukemia," Blood, vol. 109, no. 8, pp. 3496-3499, 2007.

[14] D. Li, L. Ambrogio, T. Shimamura et al., "BIBW2992, an irreversible EGFR/HER2 inhibitor highly effective in preclinical lung cancer models," Oncogene, vol. 27, no. 34, pp. 4702-4711, 2008 
[15] R. Bahleda, J. Soria, Y. Berge et al., "Phase I trial assessing safety and pharmacokinetics of afatinib (BIBW 2992) with intravenous weekly vinorelbine in advanced solid tumors," Journal of Clinical Oncology, vol. 29, no. 15, supplement, p. 2585, 2011.

[16] F. Solca, G. Dahl, A. Zoephel et al., "Target binding properties and cellular activity of afatinib (BIBW 2992), an irreversible ErbB family blocker," Journal of Pharmacology and Experimental Therapeutics, vol. 343, no. 2, pp. 342-350, 2012.

[17] V. A. Miller, V. Hirsh, J. Cadranel et al., "Afatinib versus placebo for patients with advanced, metastatic non-small-cell lung cancer after failure of erlotinib, gefitinib, or both, and one or two lines of chemotherapy (LUX-Lung 1): a phase $2 b / 3$ randomised trial," The Lancet Oncology, vol. 13, no. 5, pp. 528538, 2012.

[18] J. C. H. Yang, J. Y. Shih, W. C. Su et al., "Afatinib for patients with lung adenocarcinoma and epidermal growth factor receptor mutations (LUX-Lung 2): a phase 2 trial," The Lancet Oncology, vol. 13, no. 5, pp. 539-548, 2012.

[19] L. V. Sequist, J. C.-H. Yang, N. Yamamoto et al., "Phase III study of afatinib or cisplatin plus pemetrexed in patients with metastatic lung adenocarcinoma with EGFR mutations," Journal of Clinical Oncology, vol. 31, no. 27, pp. 3327-3334, 2013.

[20] Y.-L. Wu, C. Zhou, C.-P. Hu et al., "Afatinib versus cisplatin plus gemcitabine for first-line treatment of Asian patients with advanced non-small-cell lung cancer harbouring EGFR mutations (LUX-Lung 6): an open-label, randomised phase 3 trial," The Lancet Oncology, vol. 15, no. 2, pp. 213-222, 2014.

[21] T. Y. Seiwert, J. Fayette, D. Cupissol et al., "A randomized, phase II study of afatinib versus cetuximab in metastatic or recurrent squamous cell carcinoma of the head and neck," Annals of Oncology, vol. 25, no. 9, pp. 1813-1820, 2014.

[22] S. Cheng, J. Ma, A. Guo et al., "BTK inhibition targets in vivo CLL proliferation through its effects on B-cell receptor signaling activity," Leukemia, vol. 28, no. 3, pp. 649-657, 2013.

[23] L. A. Honigberg, A. M. Smith, M. Sirisawad et al., "The Bruton tyrosine kinase inhibitor PCI-32765 blocks B-cell activation and is efficacious in models of autoimmune disease and B-cell malignancy," Proceedings of the National Academy of Sciences of the United States of America, vol. 107, no. 29, pp. 13075-13080, 2010.

[24] D. Wodarz, N. Garg, N. L. Komarova et al., "Kinetics of CLL cells in tissues and blood during therapy with the BTK inhibitor ibrutinib," Blood, vol. 123, no. 26, pp. 4132-4135, 2014.

[25] J. R. Brown, "Ibrutinib (PCI-32765), the first BTK (Bruton's tyrosine kinase) inhibitor in clinical trials," Current Hematologic Malignancy Reports, vol. 8, no. 1, pp. 1-6, 2013.

[26] P. Stopfer, K. Marzin, H. Narjes et al., "Afatinib pharmacokinetics and metabolism after oral administration to healthy male volunteers," Cancer Chemotherapy and Pharmacology, vol. 69, no. 4, pp. 1051-1061, 2012.

[27] Food and Drug Administration, Afatinib @ Approved Drugs, Food and Drug Administration, 2013, http://www.fda.gov/ Drugs/InformationOnDrugs/ApprovedDrugs/ucm360574.htm.

[28] Food and Drug Administration, Ibrutinib @ Approved Drugs, FDA, 2013, http://www.fda.gov/Drugs/InformationOnDrugs/ ApprovedDrugs/ucm374857.htm.

[29] Food and Drug Administration, Ibrutinib @ Approved Drugs, FDA, 2014, http://www.fda.gov/Drugs/InformationOnDrugs/ ApprovedDrugs/ucm385878.htm.
[30] C. Bardin, G. Veal, A. Paci et al., "Therapeutic drug monitoring in cancer-are we missing a trick?" European Journal of Cancer, vol. 50, pp. 2020-2036, 2014.

[31] P. Hubert, J.-J. Nguyen-Huu, B. Boulanger et al., "Harmonization of strategies for the validation of quantitative analytical procedures: a SFSTP proposal-part I," Journal of Pharmaceutical and Biomedical Analysis, vol. 36, no. 3, pp. 579-586, 2004.

[32] P. Hubert, J.-J. Nguyen-Huu, B. Boulanger et al., "Harmonization of strategies for the validation of quantitative analytical procedures. A SFSTP proposal-part II," Journal of Pharmaceutical and Biomedical Analysis, vol. 45, no. 1, pp. 70-81, 2007.

[33] P. Hubert, J.-J. Nguyen-Huu, B. Boulanger et al., "Harmonization of strategies for the validation of quantitative analytical procedures. A SFSTP proposal-Part III," Journal of Pharmaceutical and Biomedical Analysis, vol. 45, no. 1, pp. 82-96, 2007.

[34] S. Hambÿe, D. Stanicki, J.-M. Colet, E. M. Aliouat, J. J. Vanden Eynde, and B. Blankert, "Three optimized and validated (using accuracy profiles) LC methods for the determination of pentamidine and new analogs in rat plasma," Talanta, vol. 83, no. 3 , pp. 832-839, 2011.

[35] D. H. Shewiyo, E. Kaale, P. G. Risha et al., "Accuracy profiles assessing the validity for routine use of high-performance thinlayer chromatographic assays for drug formulations," Journal of Chromatography A, vol. 1293, pp. 159-169, 2013.

[36] J. M. Mermet and G. Granier, "Potential of accuracy profile for method validation in inductively coupled plasma spectrochemistry," Spectrochimica Acta, Part B Atomic Spectroscopy, vol. 76, pp. 214-220, 2012.

[37] G. Mercier and C. Campargue, "Partially hydrolyzed guar gum characterization and sensitive quantification in food matrices by high performance anion exchange chromatography with pulsed amperometric detection-validation using accuracy profile," Journal of Chromatography A, vol. 1262, pp. 180-187, 2012.

[38] V. Varlet, F. Smith, and M. Augsburger, "Accuracy profile validation of a new analytical method for butane measurement using headspace-gas chromatography-mass spectrometry," Journal of Chromatography B, vol. 913-914, pp. 155-160, 2013.

[39] V. Varlet, E. L. de Croutte, M. Augsburger, and P. Mangin, "Accuracy profile validation of a new method for carbon monoxide measurement in the human blood using headspacegas chromatography-mass spectrometry (HS-GC-MS)," Journal of Chromatography B, vol. 880, no. 1, pp. 125-131, 2012.

[40] M. Helvenstein, S. Hambye, and B. Blankert, "Determination of three tyrosine kinase inhibitors and one active metabolite by an identical and validated ultra-performance liquid chromatography-DAD method in human plasma," Current Pharmaceutical Analysis, vol. 10, no. 3, pp. 161-168, 2014. 

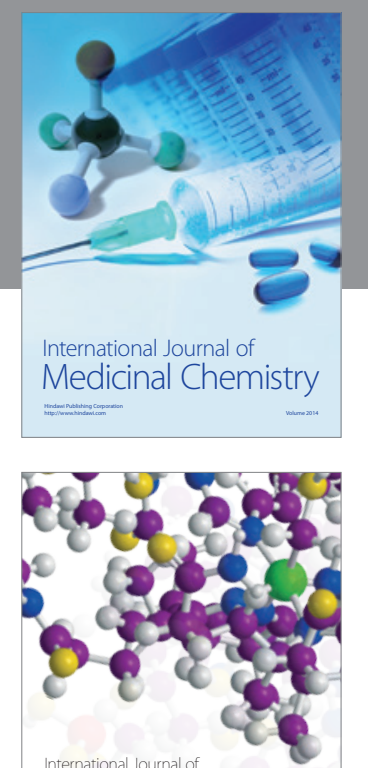

\section{Carbohydrate} Chemistry

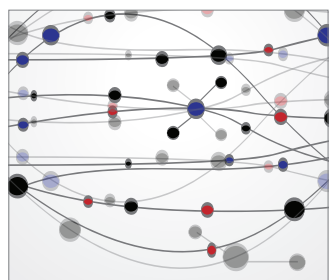

The Scientific World Journal
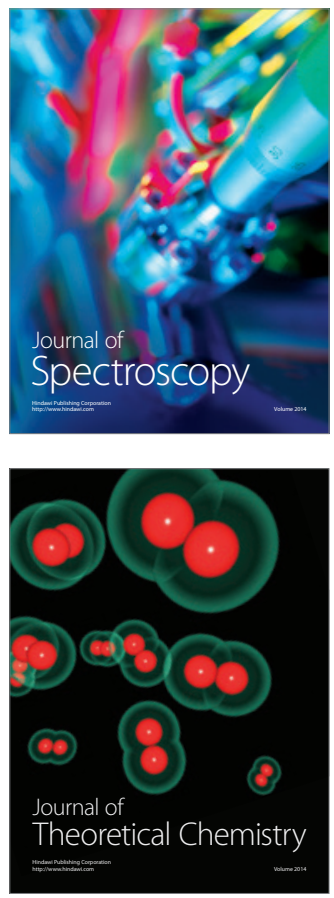
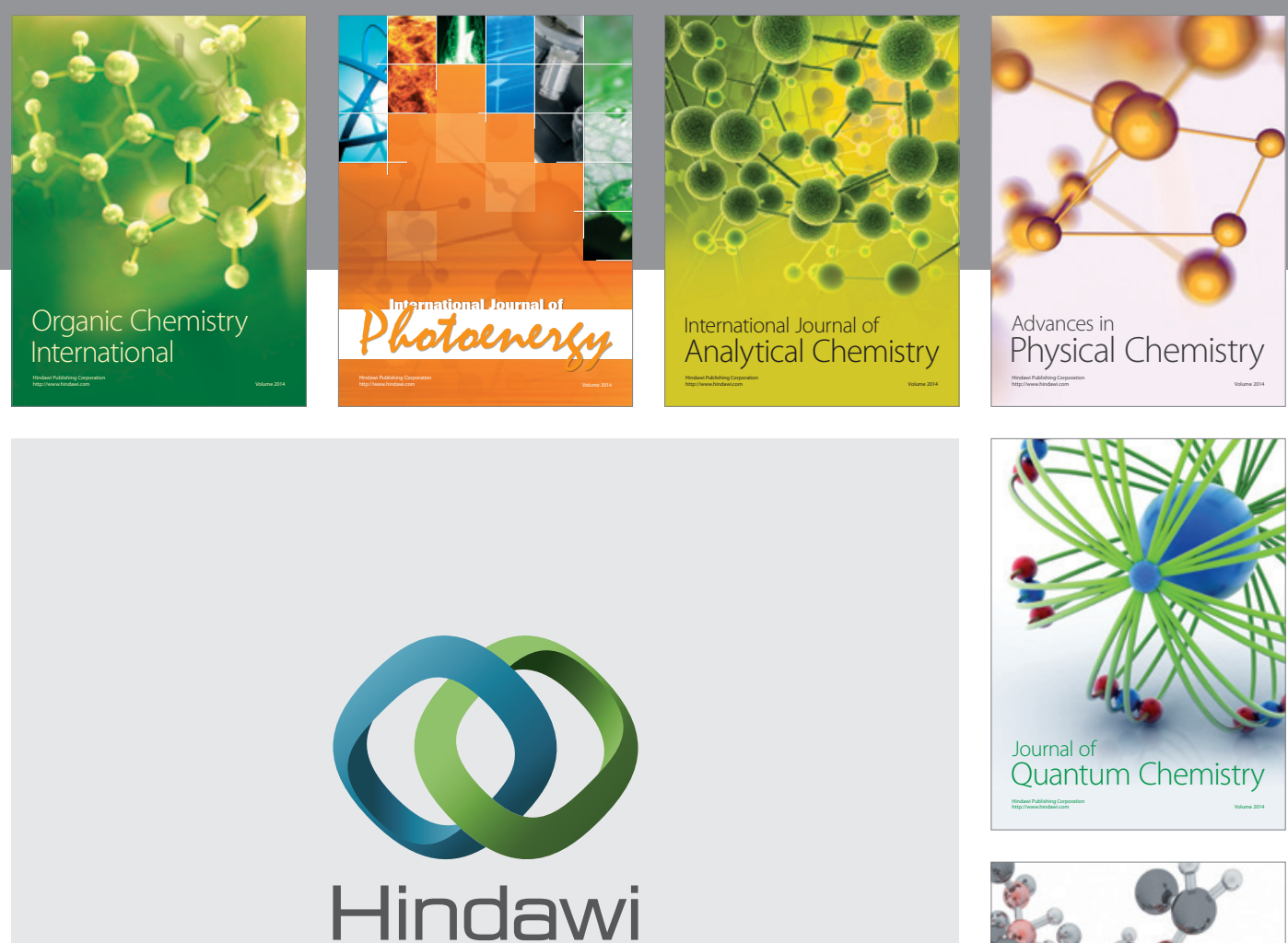

Submit your manuscripts at

http://www.hindawi.com

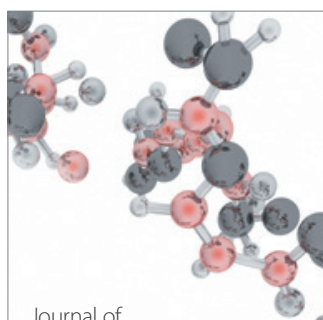

Analytical Methods

in Chemistry

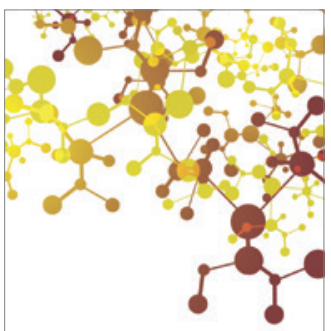

Journal of

Applied Chemistry

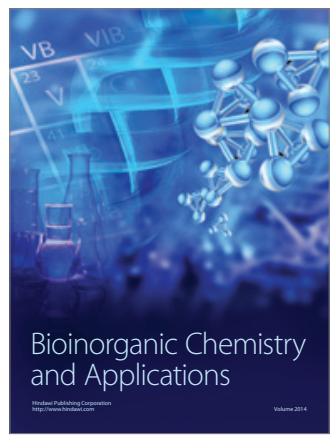

Inorganic Chemistry
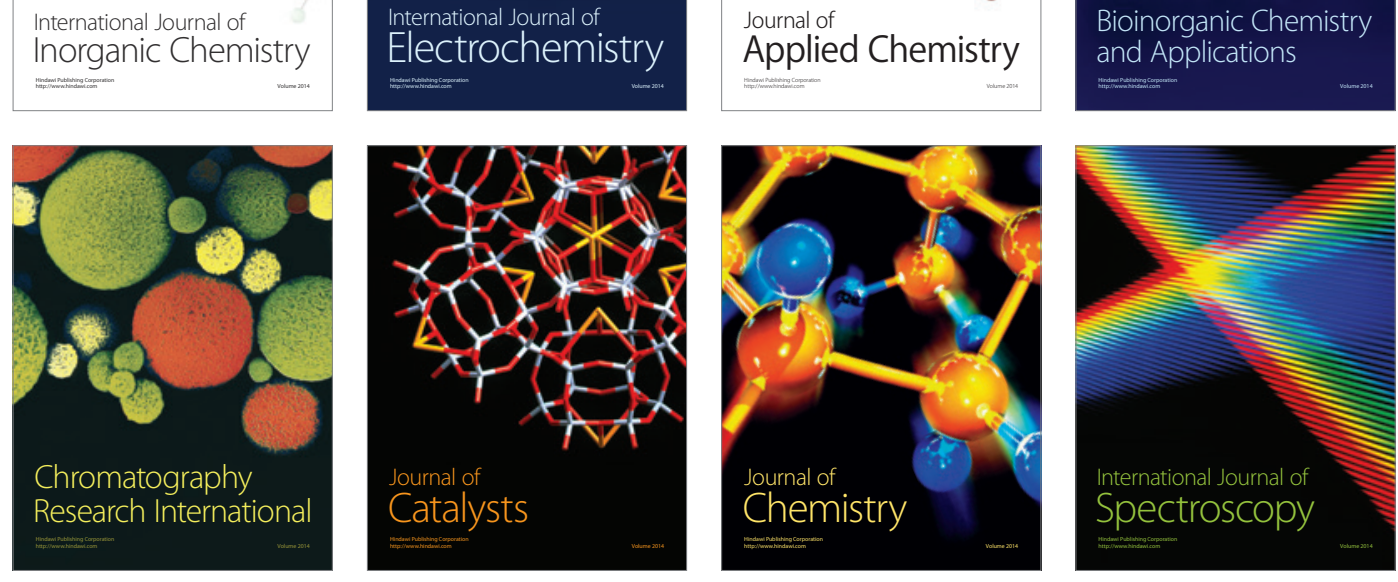